\title{
Comparison between the Empirical and Mechanistic-Empirical Pavement Design Methods
}

\author{
Dr. Mohammed Mahmoud Shallal, Eng. Elsir Suliman Ahmed \\ Newtech Consulting Group
}

\begin{abstract}
In this paper a comparative study has been carried out between the Mechanistic-Empirical Pavement Design Methods and the Empirical Pavement Design Methods. For the purpose of this paper, nine pavement design sections have been prepared using the Mechanistic-Empirical Methods represented by the Asphalt Institute Design Method (SW-1 software of the Asphalt Institute) and the Empirical Design represented by AASHTO 1993 and TRL Road Note No.31, using the same traffic loading and subgrade strength. Three traffic loading scenarios have been considered for this study.
\end{abstract}

Key words: Mechanistic-Empirical, Empirical, axle loads, Subgrade Strength, pavement design

\section{Introduction}

Design should aim at providing adequate cover to the subgrade so that the stresses at the subgrade level are low enough to prevent excessive deformation. Many design methods have been developed to suit different climatic and traffic loading conditions.

\section{Pavement Design Approaches}

Many methods of designing flexible pavement have been developed by various transportation agencies and evolved throughout the years. These methods range from very simple in concept to highly sophisticated. Although different agencies have been using design procedures that satisfy their local conditions, pavement design methods can be grouped into four distinct approaches: ${ }^{(1)}$

\subsection{Methods Based on Experience}

Many agencies have been adopting standard pavement sections for different ranges of traffic levels and environmental conditions. These standard sections are mostly based on previous experience and are applicable to local materials and budget practice. Although these methods are old, they are still being used by relatively small agencies because of their simplicity, low design cost, and reliability under certain

conditions. These methods, however, do not allow for comparison between alternatives. They also do not recognize the varying serviceability with age. These methods also assume average material properties, traffic levels, and environmental conditions. If any of these variables change, this approach looses its validity. $^{(1)}$

\subsection{Methods Based on Soil Formula or Simple Strength Tests}

These methods are based on empirical correlations between the required pavement thickness and soil classification or simple strength tests of subgrade materials such as California Bearing Ratio (CBR). This approach is also old and assumes that traffic load is mostly carried by subgrade, whereas pavement layers are mainly used for smoothness and dust control. Similar to the previous approach, these methods

are simple, have low design cost, and could be reliable under certain conditions. The disadvantages are, these methods do not recognize the varying serviceability with age. These methods also assume average pavement material properties, traffic levels, and environmental conditions. ${ }^{(1)}$

\subsection{Methods Based on Statistical Evaluation of Pavement Performance}


These methods are based on extensive field observation of pavement performance under different conditions and developing empirical relations between pavement thickness and material properties, traffic, and environmental conditions. Once these empirical relations are defined, the designer can input various input parameters and determine the required thicknesses of different layer. A typical example of this approach is the 1993 AASHTO (American Association of State Highway and Transportation Officials) design method (AASHTO, 1993). The main advantage of this approach over previous 8-10 The Handbook of Highway Engineering (C 2006 by Taylor \& Francis Group, LLC approaches is that the method considers the change of serviceability with pavement age. Thus, the designer can design a pavement section to last for a certain designed life with a predetermined serviceability level. This approach also considers in-service conditions and is not based of simple theoretical assumptions. It also allows for economic comparison between design alternatives.

This approach, however, still suffers from the dependency on empirical relations that are limited to the conditions under which they were developed. If changes occur in any input parameters such as increasing axle loads and tyre pressure or if a new pavement material is used such as modified asphalt binders, the method would not be valid. ${ }^{(1)}$

\subsection{Methods Based on Structural Analysis of Layered Systems}

This approach is more fundamental than all other approaches since it considers basic material responses such a stresses, strains, and deformations. In such cases, the traffic load is applied on a simulated multilayered-pavement system and the critical material responses are calculated. These critical response parameters are then correlated to performance using transfer functions, typically based on empirical

relations. The designer, therefore, has the capability to determine the required layer thicknesses so that the pavement would last for the required designed life without exceeding predetermined distress levels. This approach represents a major improvement over others due to its accuracy and reliability. However, this approach requires extensive testing and computations. Methods based on this approach also

incorporate empirical correlations, although the degree of empiricism is small. In addition, theoretical models require extensive calibration and verification since the incorporated assumptions may not exactly match field conditions. The proposed AASHTO mechanistic-empirical pavement design method (NCHRP, 2003) follows the

last approach. Future approaches are expected to be more rational with less, or even no, dependency on empirical relations.

\section{Design methods used:}

\subsection{AASHTO 1993 Pavement Design Method:}

The American Association of State Highway Officials (AASHO) Road Test at Ottawa, Illinois provided the basis for calculating the required pavement thickness. Models were developed that related pavement performance, vehicle loadings, strength of roadbed soils, and the pavement structure. The purpose of the AASHTO model in the pavement thickness design process is to calculate the Required Structural Number (SN). This is the strength of the pavement that must be constructed to carry the mixed vehicle loads over the roadbed soil, while providing satisfactory serviceability during the design period. Knowing the SN, the pavement layer thickness or overlay thickness can be calculated. Vehicle loads are expressed in 18-kip (80kiloNewton) Equivalent Single Axle Loads 18-kip (80-kN) ESAL. ${ }^{(2)}$

3.2 TRL Road No. 31 for Bitumen-Surface Roads: Road Note 31 (RN31), developed by the Transport \& Road Research Laboratories (TRRL) for developing countries, presents a guide to the structural design of bitumen - surfaced roads in tropical and sub - tropical countries. The fourth edition of RN31 considers the traffic loading in terms of the cumulative number of standard axles on the basis of which the type of surfacing, base and sub-base are selected. This edition extended the design of previous editions to cater for traffic up to 30 million equivalent standard axles. It also has accommodated variability in materials properties, traffic forecasts, effect of climate and the axle loads. Also the range of structures has been expanded to provide more detailed advice on specifications and techniques. It provides eight traffic classes ranges from $\mathrm{T} 1$ to $\mathrm{T} 8$. $\mathrm{T} 1$ represents the traffic that less than 0.3 million ESA during the design period, while T8 represents the traffic that between 17 million ESA and 30 million ESA, during the design period. 
The road note 31 (4th edition), provides six classes of subgrade strength in terms of CBR, that ranges from $2 \%$ to $30 \%$. For the prepared designs, the RN31-4th edition provides eight design charts. Each design chart consists of many designs according to the two main factors prescribed above; the traffic and the subgrade strength. ${ }^{(3)}$

3.3 The Asphalt Institute Method for Structural Thickness Design for Pavements: the Asphalt Institute method for structural thickness design for pavements allows various combinations of asphalt concrete, emulsified asphalt and granular layers. It offers guidelines for defining subgrade properties, material properties and traffic values required for the selection of appropriate thickness of the pavement layers. In this design procedure the pavement is regarded as a multi-layered elastic system. The materials in each layer are characterized by a modulus of elasticity $(E)$ and Poisson, $s$ ratio $(\mu)$. Traffic is expressed in terms of repetitions of an equivalent $80 \mathrm{KN}(18000 \mathrm{Ib})$ single-axle load applied to the pavement on two sets of dual tires. For pavements composed of full-depth asphalt layers the pavement is regarded as a three-layer system. The pavement with the untreated aggregate is considered a four-layer system. The subgrade, the lowest layer, is assumed infinite in the vertically downward and horizontal directions. The other layers, of finite thickness, are assumed infinite in the extent in the horizontal directions. ${ }^{(4)}$

\section{The Design Software of the Asphalt Institute SW-1:}

Computer Programs Various computer programs based on Burmister's layered theory have been developed . The earliest and the best known is the CHEV program developed by the Chevron Research Company (Warren and Dieckmann, 1963). The program can be applied only to linear elastic materials but was modified by the Asphalt Institute in the DAMA program to account for nonlinear elastic granular materials (Hwang and Witczak, 1979). ${ }^{(6)}$

SW-1 was designed for pavement design professionals who may need to design pavements for a wide variety of uses including airports, roadways, and parking lots. SW-1 provides a computerized methodology for thickness design of asphalt pavements for a wide variety of pavement uses. SW-1 is based on the respected design procedures of the Asphalt Institute as detailed in several Asphalt Institute manual series

(MS), information series (IS), and research report (RR) documents. These methods are based on mechanistic-empirical principles and have been developed and refined over a period of 30 years by the Asphalt Institute. SW-1 is a new Microsoft Windows-based computerized method for pavement thickness design that builds upon four familiar Asphalt Institute DOS computer programs for pavement design. The four DOS-base programs were DAMA (CP-1), HWLOAD (CP-2), AIRPORT (CP-3), and HWY (CP-4) (49). The developers of SW-1 embedded the original computational algorithms from DAMA, HWLOAD, AIRPORT, and HWY into SW-1 and developed a new Windows user-interface to collect input data, report output, and manage data files. SW-1 uses the resilient modulus to characterize subgrade stiffness, but can correlate from CBR or R-values are the user has this type of information. The user is asked to select the type of strength measure, input the stiffness values, and select design subgrade value in order to calculate the Design Subgrade Resilient Modulus. CBR and R-value correlations of the Asphalt Institute are considered applicable to fine-grained soils classified as CL, CH, ML, SC, SM, and SP (Unified Soil Classification) or for materials that are estimated to have a resilient modulus of 30,000 psi, or less. These correlations are not applicable to granular materials, such as base aggregate, which may require direct laboratory testing to obtain resilient modulus values or using other correlations. ${ }^{(5)}$ 


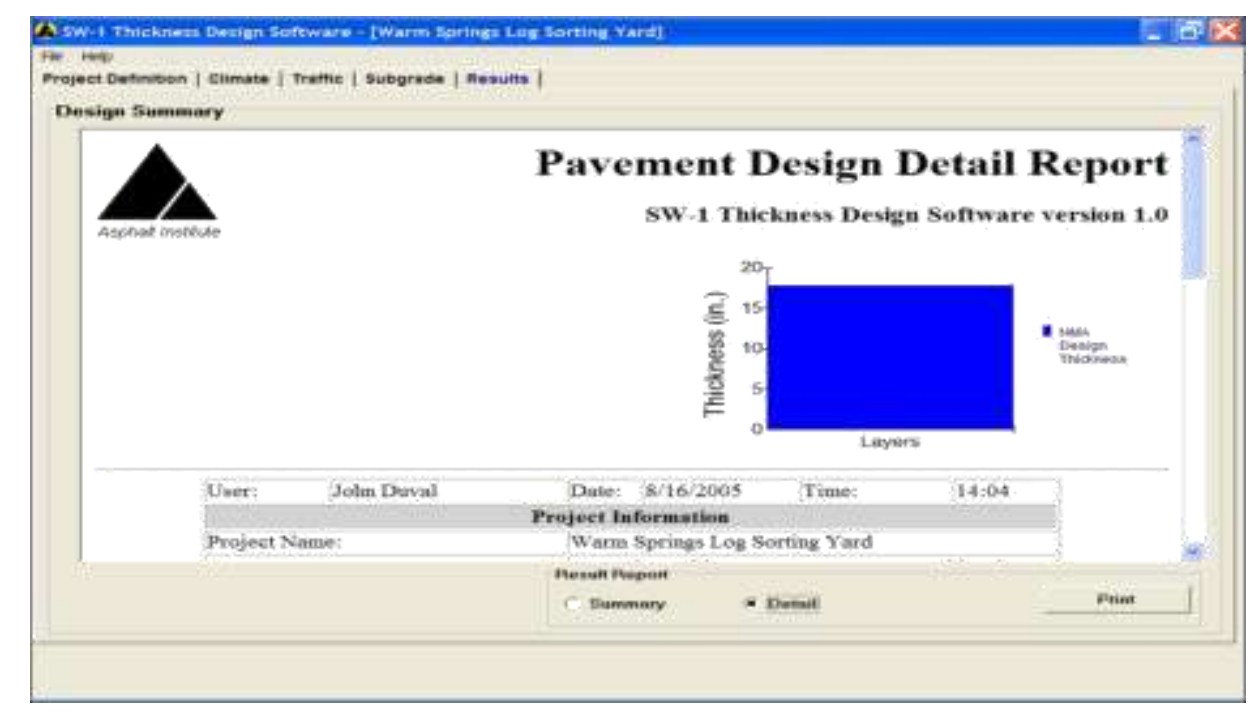

Chart No. (1): SW-1 Design Report

\section{The Pavement Design Sections:}

4.1 Design Methods Used: For the purpose of this study, three pavement design methods have been used, two methods are representing the Empirical and Semi- Empirical Pavement Design Methods namely TRL Road Note No.31 and AASHTO 1993, and the third one is the Asphalt Institute method representing the Mechanistic-Empirical Design Methods. The pavement design software (SW-1) of the Asphalt Institute has been used to prepare the pavement design sections.

4.2 Traffic Loading: Three traffic loading scenarios has been used to develop the pavement design sections; (1-3 million ESA), (3-10 million ESA) and (10-20 million ESA). These traffic loading ranges exist in the traffic loading categories provided in the road note No.31, so have been used as they are. But for AASHTO 1993 \& Asphalt Institute Methods, the traffic loading considered in the mid of the category.

4.3 Subgrade Strength: One value of $(\mathrm{CBR}=15 \%)$ has been used representing the subgrade strength against the three loading scenarios. The California Bearing Ratio (CBR) is used directly in the TRL Road Note No. 31 Design Charts, but it needs to be converted into Resilient Modulus $\left(\mathrm{M}_{\mathrm{R}}\right)$ to be used in the AASHTO 1993 Design Method and the Asphalt Institute Design Method. The Asphalt Institute correlation of $(1 \mathrm{CBR}=1500 \mathrm{PSI})$ is applicable only for fine soils. Accordingly the correlation chart of (Van Til et al $1972)^{3}$ has been used. The $M_{R}$ equivalent to $15 \% \mathrm{CBR}$ is found as $90 \mathrm{Mpa}$.

4.4 The obtained Pavement Sections: the table No. (1) below summarizes the obtained pavement sections using:

$>$ Design Charts of the TRL Road Note No. 31.

$>$ AASHTO 1993 Pavement Design Method.

$>$ SW-1 (the Pavement Design software of the Asphalt Institute).

All of the pavement structures considered in this study are simple three/two layer flexible structures, consisting of an asphalt concrete (AC) on top of a granular base/subbase. The full depth asphalt and the emulsified asphalt were not considered in this comparative study. 
Table No. (1): The obtained Pavement Sections

\begin{tabular}{|c|c|c|c|c|}
\hline \multirow[t]{2}{*}{ Design Data } & \multirow[t]{2}{*}{ Description } & \multicolumn{3}{|c|}{ Pavement Design Section Using } \\
\hline & & $\begin{array}{c}\text { Road Note } \\
\text { No. } 31 \\
\text { Design } \\
\text { Charts }\end{array}$ & $\begin{array}{c}\text { AASHTO } \\
1993 \text { Design } \\
\text { Method }\end{array}$ & $\begin{array}{c}\text { Asphalt } \\
\text { Institute } \\
\text { Design } \\
\text { Software } \\
\text { SW-1 }\end{array}$ \\
\hline \multirow{4}{*}{$\begin{array}{l}\mathrm{T}=(1-3) * \\
10^{6} \mathrm{ESA} \\
\mathrm{S}=15 \%\end{array}$} & Asphalt Concrete & 50 & 75 & 150 \\
\hline & Base & 175 & 200 & 300 \\
\hline & Subbase & 125 & 125 & 0 \\
\hline & Pavement S.N & 2.35 & 2.93 & 4.37 \\
\hline \multirow{4}{*}{$\begin{array}{c}\mathrm{T}=(3-10) * \\
10^{6} \mathrm{ESA} \\
\mathrm{S}=15 \%\end{array}$} & Asphalt Concrete & 50 & 100 & 150 \\
\hline & Base & 200 & 200 & 470 \\
\hline & Subbase & 175 & 200 & 0 \\
\hline & Pavement S.N & 2.68 & 3.61 & 5.45 \\
\hline \multirow{4}{*}{$\begin{array}{c}\mathrm{T}=(10-20) * \\
10^{6} \mathrm{ESA} \\
\mathrm{S}=15 \%\end{array}$} & Asphalt Concrete & 150 & 150 & 300 \\
\hline & Base & 250 & 250 & 450 \\
\hline & Subbase & 100 & 100 & 0 \\
\hline & Pavement S.N & 4.41 & 4.41 & 7.8 \\
\hline
\end{tabular}

T: Traffic loading, S: Subgrade Strength, S.N: Structural Number

4.5 Calculations of the structural numbers: the structural number for each pavement section has been calculated using the AASHTO 1993 equation:

$$
S N=a_{1} D_{1}+a_{2} m_{2} D_{2}+a_{3} m_{3} D_{3}
$$

Where (SN: Structural Number, a: layer coefficient, m: drainage coefficient). 


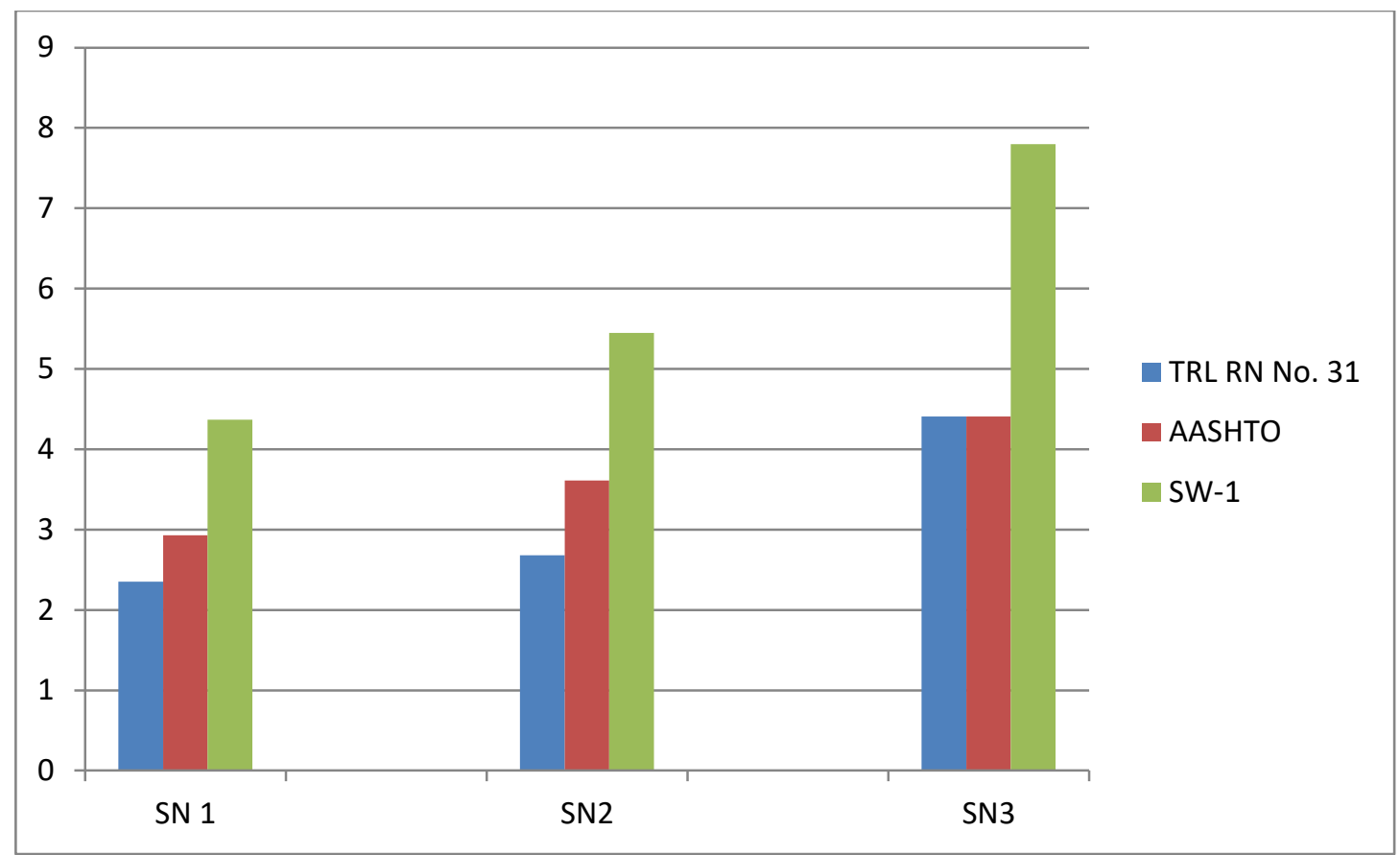

Chart No. (2): The Structural numbers of the obtained Pavement Section

\section{Discussion \& Conclusion:}

A. In this comparative study, pavement design sections prepared using the Mechanistic-Empirical Methods represented by the Asphalt Institute Pavement Design Method (SW-1 software of the Asphalt Institute) and the Empirical Pavement Design represented by AASHTO 1993 and TRL Road Note No.31.

B. Three scenarios of traffic loading has been selected (1-3 Million ESA), (3-10 Million ESA) and (1020 Million ESA) respectively. One value of subgrade strength has been used in the three scenarios $\left(\mathrm{CBR}=15 \%\right.$ when using TRL RN31 and equivalent to $\mathrm{M}_{\mathrm{R}}=90 \mathrm{Mpa}$ when using AASHTO 1993 or Asphalt Institute methods).

C. The obtained pavement design sections and their calculated structural numbers shows the following:

- The Mechanistic-Empirical methods (Asphalt Institute) give thicker pavements compared to the Empirical methods (TRL Road Note No.31 \& AASHTO 1993), especially on the Asphalt Concrete layer.

- In the first Scenario, the asphalt concrete (AC) layer thickness obtained by the SW-1 (Asphalt Institute) is two times the AC using AASHTO 1993 and three times the AC using the RN 31. The thickness of the aggregate base layer of the Asphalt Institute (no subbase) is almost equal to the thickness of the base \& subbase together using AASHTO 1993 \& RN 31.

\section{Recommendations:}

The Asphalt Institute as a Mechanical Empirical method has many advantages over the empirical methods, considering the horizontal tensile strain at the bottom of the asphalt layer to minimize fatigue cracking and considering the vertical compressive strain on the top of subgrade to reduce the permanent deformation. The Asphalt Institute method of Design assures very little strength for aggregate base which result in thick asphalt concrete. The obtained design sections in this study showed thick asphalt layer compared to the other two empirical methods, which affecting the construction costs. Therefore it is advisable to do the following:

- Avoid designing roads on weak subgrades, and if the subgrade strength is low, some kind of improvement should be done. This helps to get reasonable design thickness.

- The Asphalt Institute recommends using $130 \mathrm{~mm}$ minimum AC for heavy traffic. The last scenario of loading in this study shows $300 \mathrm{~mm}$ AC and $450 \mathrm{~mm}$ base. So conversion factors 
can be used to convert part of the AC in granular layer, keeping the minimum $\mathrm{AC}$, and this can contribute to reduce the cost of construction.

- As traffic forecasting has always been a source of uncertainty, and results in big difference in the thickness using different methods, it is advisable to use shorter design lives.

\section{References:}

[1] T.F.FWA, 2006, the Handbook of Highway Engineering.

[2] Florida Department of Transportation, January 2005, Flexible Pavement Design Manual.

[3] TRL, 1993, Road Note 31: A guide to the structural design of bituminous surfaced roads in tropical and sub-tropical countries, 4th edition, London.

[4] Asphalt Institute, 2008, Asphalt Pavements for Highways \& Streets, Manual Series No.1 (MS-1), 9th edition, Lexington, KY, USA.

[5] Asphalt Institute, 2005, User' Guide for Asphalt Pavement Design Software for Highways, Airports, Heavy Wheel Loads and other applications (SW-1).

[6] Yang H.Huang (2004), Pavement Analysis and Design.

[7] AASHTO (1993), Guide for the Design of Pavement Structures, American Association of State Highway and Transportation Officials, Washington, D.C.

[8] AASHTO (2008), Mechanistic-Empirical Pavement Design Guide, American Association of State Highway and Transportation Officials, Washington, D.C.

[9] Texas Department of Transportation (TxDOT), 2011, Pavement Design Guide, published by Texas Department of Transportation.

[10] Mohammed Mahmoud Shallal, 2010, paper on: Traffic Loading for Pavement Design, published by Journal of Building and Road Research, volume 9, Building \& Road Research Institute, University of Khartoum, Sudan.

[11] Mohammed Mahmoud Shallal, 2014, paper on: Rational Structural Designs for Highways in Different Climatic Zones in Sudan, published by IOSR Journal of Engineering, volume 4. 